\title{
Effect of Platform Swing Walkway on Locomotor Behavior in Children With Diplegic Cerebral Palsy: Randomized Controlled Trial
}

Hanaa Mohsen, PhD; Omnya Samy, MSc

Department of Physical Therapy for Pediatrics and Pediatric Surgery, College of Physical Therapy, Badr University, Cairo, Egypt

\section{Corresponding Author:}

Hanaa Mohsen, PhD

Department of Physical Therapy for Pediatrics and Pediatric Surgery

College of Physical Therapy

Badr University

Badr City

Cairo, 022

Egypt

Phone: 2001009106127

Email: $\underline{\text { hanaa753@gmail.com }}$

\section{Abstract}

Background: Limited attention has been given to the effectiveness of the platform swing walkway, which is a common way to improve gait pattern through activation of sensory stimuli (visual, auditory, vestibular, and somatosensory).

Objective: The objective of this study was to determine the effect of a platform swing walkway on gait parameters in children with diplegic cerebral palsy (CP).

Methods: A total of 30 children of both sexes (aged 6-8 years) with diplegic CP were enrolled in this study. They were randomly assigned into two groups of equal number: the control group $(n=15)$ and the study group $(n=15)$. The control group received the conventional physical therapy plan, whereas the study group received the same conventional physical therapy program in addition to gait training on a platform swing walkway. Temporal parameters during the gait cycle were collected using gait tracker video analysis, and the Growth Motor Function Measure Scale (GMFM-88) was used to assess standing and walking (Dimensions D and E) before and after the treatment program.

Results: A statistically significant improvement in both groups was noted when comparing the mean values of all measured variables before and after treatment $(P \leq .05)$. There were significant differences between the control and study groups with respect to all measured variables, which favored the study group when comparing the posttreatment outcomes $(P \leq .05)$.

Conclusions: Results suggest that gait training on platform swing walkways can be included as an alternative therapeutic modality to enhance gait parameters and gross motor function in children with diplegic $\mathrm{CP}$.

Trial Registration: ClinicalTrials.gov NTC04246658; https://clinicaltrials.gov/ct2/show/NTC04246658

(JMIR Biomed Eng 2020;5(1):e18232) doi: 10.2196/18232

\section{KEYWORDS}

cerebral palsy; platform swing walkway; spastic diplegia

\section{Introduction}

Cerebral palsy $(\mathrm{CP})$ occurs as a result of prenatal or postnatal lesion in the developing brain of a fetus or infant, which mainly affects motor activity [1]. Because of the complex relationship between primary and secondary motor symptoms in $\mathrm{CP}$, for example, between spasticity and muscle contracture, the diagnosis of gait impairments varies between patients. As a result of irregular muscle activity or bone loading, secondary impairments can develop over time, such as shortened muscles, which limit the joint range of motion. Both primary and secondary impairments manifest in a pathological pattern of $\mathrm{CP}$ gait [2].

In children with spastic diplegia, abnormal muscle tone can lead to medial femoral torsion and compensatory external tibial torsion, which result in in-toing and crouch gait, thereby 
decreasing the stability during walking [3]. This gait disorder decreases the base of support in the stance phase and increases crossing of the legs in the swing phase that increases the risk of falling and leads to functional balance problems [4].

Locomotion arises from intricate dynamic interactions between a central program and feedback mechanisms. This central program relies on a genetically determined spinal circuit capable of generating basic locomotion patterns, as well as neural drive through various descending pathways that can trigger, stop, and/or steer locomotion. Sensory feedback from muscle and skin afferents, as well as other sensory modalities (vision, audition, vestibular), dynamically adapts the locomotion pattern to the requirements of the environment [5].

Researchers have demonstrated that symmetric weight-bearing training on unstable surface improves patients' performance in activities of daily living, by using, for example, auditory feedback, task-orientation training, and lower extremity elevation method [6]. In particular, unstable surface has been shown to enhance ankle and knee joint stability, lower extremity strength, muscle activation, proprioception, and balance control [7-9]. In addition, unstable surface has been reported to be more effective than other techniques for reducing postural sway while maintaining the standing position [10]. Chaudhuri and Aruin [6] stated that individuals with hemiparesis exposed to platform translations showed improved balance control seen as decreased latency and increased strength of the paretic leg force response.

However, most studies conducted to date have only evaluated the effects of platform swing on balance ability. Little is known about the effects of platform swing on lower extremity function, especially walking performance. Therefore, the purpose of this study was to examine the effects of platform swing walkway on gait parameters and gross motor function in children with diplegic CP.

\section{Methods}

\section{Study Design}

This is a randomized, single-blind, controlled clinical trial. Eligible children were recruited from the Faculty Physical Therapy Outpatient Clinic, Cairo University, Badr University in Cairo and Prof Dr Kamal Shoukry pediatric rehabilitation center.

\section{Participants}

The study recruited 30 children with diplegic $\mathrm{CP}$ of both sexes (18 boys and 12 girls). Children were included only if they met the following inclusion criteria: aged between 6 and 8 years, diagnosed with diplegic $\mathrm{CP}$ (which was verified with magnetic resonance images collected from medical records), having spasticity of Grade 1 upper limb to $1+$ lower limb on the Modified Ashworth Scale (MAS) [11], in Level II or III according to the Gross Motor Function Classification System [12], used the standard orthotic management according to their individual abilities, and were cognitively capable and competent for interpreting and following instructions. Children who had vision or hearing problems, previous surgery of the lower extremities, botulinum injections of the lower limb muscles within the preceding 6 months, and suffering from cardiopulmonary disorders were excluded. Prior to data collection, the study purposes, procedures, and benefits were fully explained to the parents of the participating children. All parents gave informed consent to have their children participate in the study. This randomized controlled study was approved by the Ethical Review Committee of the Faculty of Physical Therapy, Cairo University (Approval no. P.T.REC/012/002511).

\section{Randomization}

A total of 43 children with diplegic $\mathrm{CP}$ were recruited for this study; 9 children did not meet the inclusion criteria, and the parents of 4 children refused to give consent. Following the baseline examination, concealed allocation was performed using a computer-generated randomized table of letters created prior to the start of data collection by a researcher not involved in the recruitment or treatment of patients. Individual and sequentially lettered index cards were used to randomly assign participants to the treatment groups. The index cards were folded and placed in sealed, opaque envelopes. A second therapist, blinded to baseline examination findings, opened the envelope and proceeded with treatment according to the group assignment. Each participant received a sealed envelope containing one of the letters A or B. The flowchart of the experimental design is shown in Figure 1. 
Figure 1. Participants' flow diagram.

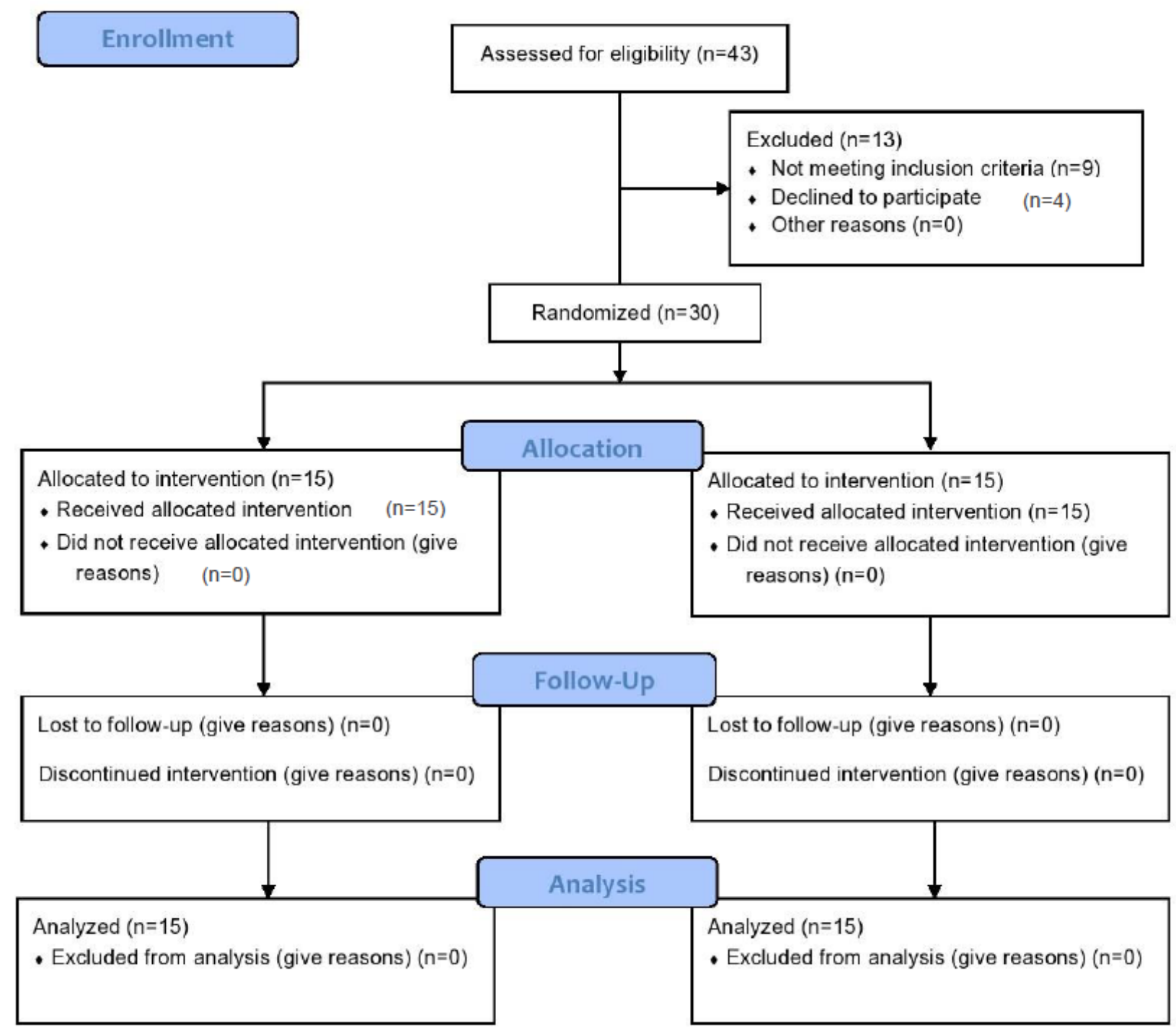

\section{Data Collection Procedures}

All procedures were performed at baseline (pretreatment) and at the end of 3 successive months of treatment (posttreatment) in a warm, lighted, and quiet room.

\section{Gross Motor Functional Measurement}

The Growth Motor Function Measure Scale (GMFM) is an observational assessment tool incorporating 88 items (GMFM-88), scored on a 4-point ordinal scale (ranging from 0 to 3) [13]. It is further subdivided into 5 domains: (A) lying and rolling; (B) sitting; (C) crawling and kneeling; (D) standing; and (E) walking, running, and jumping. In this study, only the complete dimensions $\mathrm{D}$ and $\mathrm{E}$ were assessed before and after the treatment program. We calculated the dimensions $(\%)$ as follows: (D) Standing (Total Dimension D/39) $\times 100=\%$; (E) Walking (Total Dimension E/72) $\times 100=\%$.

\section{Gait Tracker Video Analysis}

In this analysis, a 2D kinematic analysis of the lower limb sagittal plane was performed using a single video frame. It provides unilateral joint kinematics data of the hip, knee, and ankle in the sagittal plane, along with the estimation of gait events and spatiotemporal parameters. The precision of the spatiotemporal parameters estimation was found to be appropriate for clinical use [14]. Participating children were asked to walk at a self-selected velocity along a 2-m walkway. A digital video camera (Canon) was set up to record the children in the sagittal plane on a level tripod, perpendicular to the center of the pathway at a distance of $3 \mathrm{~m}$. As the lower limb will be analyzed, the camera was aligned with the knee and set to view the $2 \mathrm{~m}$ of the walkway, which ensured that the calibration area covered the lower limb. The recorded video was analyzed using Tracker software [15]. 


\section{Intervention}

\section{Platform Swing Walkway Features}

The platform swing walkway (Figure 2) comprises the following: (1) a durable vestibular metal frame consisting of a ceiling surface and upright metal bars. It has a working load with a floor space of $3 \mathrm{~m}$ width $\times 90 \mathrm{~cm}$ depth and a height of $2 \mathrm{~m}$; (2) 6 iron chains (length: $150 \mathrm{~cm}$ ) with a ceiling hook used for attaching vestibular components to the architectural suspension points; (3) a hard wooden platform swing (floor space: $2.44 \mathrm{~m}$ width $\times 70 \mathrm{~cm}$ depth) that is set $50 \mathrm{~cm}$ above the ground (floor). The swing is completely coated with Tumble Forms and contains the hardware for attaching the suspension iron chain; (4) 12 ropes of length $1.22 \mathrm{~cm}$ with 2 hooks that are used for attaching the iron chains which provide adjustable side rails and safety for children while walking. Height adjustment assembly allows for quick changes in horizontal position. Removable components allow for portability and ease of storage, as well as provide linear acceleration in forward-backward and side-to-side directions.

Figure 2. Dynamic Platform Swing Walkway.

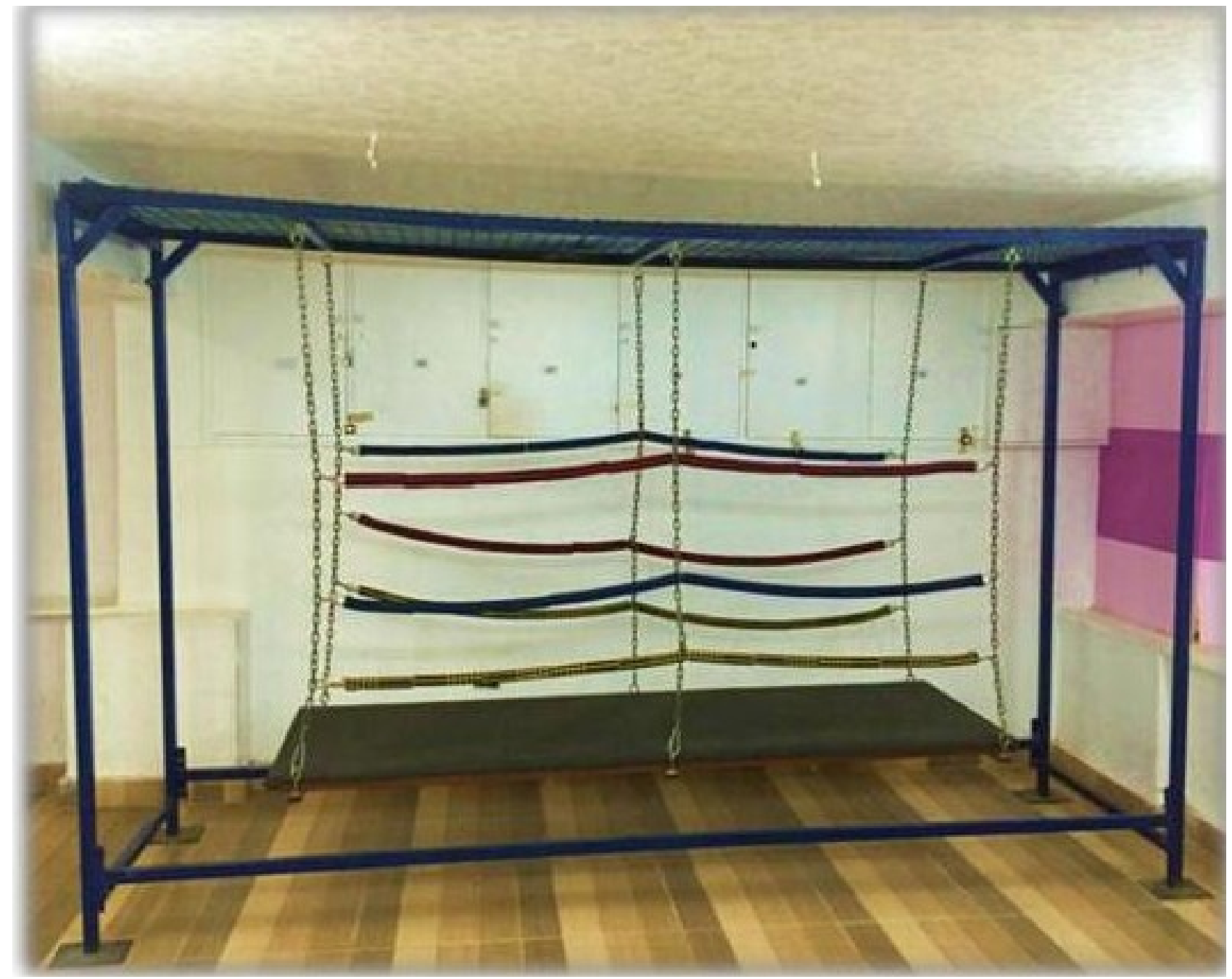

\section{The Control Group}

Children in the control group received the conventional physiotherapy program which consisted of facilitation of postural mechanism; proprioceptive training, including weight-bearing activities for upper and lower limbs; strengthening exercise for the back, abdominal muscles, hip flexors, ankle dorsiflexors, knee flexors, knee extensors, hip extensors, hip abductors, and hip internal and external rotators; standing exercise (standing holding on, standing alone with arms free, standing holding on and asking the child to lift one foot, standing on one leg, and standing on balance board); gait training activities in different directions at different speeds (walking up and down the stairs, jumping in place, and broad jumping). The duration of the program was 1 hour, and required to be performed 3 days a week for 12 weeks.

\section{The Study Group}

Children in the study group received the same physical therapy program given to the control group for 45 minutes. They additionally received gait training on a platform swing walkway for 15 minutes, which included the following steps: (1) The therapist put the child on the platform, and (2) encouraged the child to stand on the platform in a relaxed state and to hold cords of the walkway; (3) the child was then asked to walk on the platform in forward and backward directions to make sure that he or she adapted to the situation before swinging; (4) the child was asked to overcome simple obstacles such as a stepper and 
a separator. This program was performed 3 days a week for 12 weeks.

\section{Data Analysis}

$\mathrm{G}$ power analysis (power $=0.8, \alpha=.05$, effect size=0.5) determined a sample size of 30 for this study. Descriptive statistics of mean and standard deviation were calculated for all measured variables. Parametric tests (paired $t$ test and unpaired $t$ test) were used to analyze the pre- and posttreatment mean values of GMFM-88. In addition, gait cycle time (seconds) for right and left stance and swing phase was calculated. SPSS (version 20 for Windows; IBM Corp) was used for data analysis. Statistical tests were considered significant if $P \leq .05$.

\section{Results}

Table 1 presents age, weight, and height of children in the study and control groups. There was no significant difference between both groups in mean (SD) age, weight, and height $(P \leq .05)$. Table 2 presents the comparison between groups in the standing and walking tasks. There were no significant differences in pretreatment mean values between the groups in the variables measured: standing $(P=.97)$ and walking $(P=.91)$. However, when comparing the posttreatment mean values in the standing and walking tasks between the study and control groups, significant differences ( $P=.004$ and .001 , respectively) in favor of the study group were found.

Table 3 presents the results of within-group comparison in the standing and walking tasks for the two groups. Upon comparing their pre- and posttreatment values, there was a significant improvement in all measured variables in both groups $(P \leq .05)$.

Table 4 compares the results between the two groups in the stance and swing phases. There were no significant differences in pretreatment mean values between the study and control groups in the variables measured with regard to the stance of the right $(P=.64)$ and left limbs $(P=.66)$ nor with regard to the swing of the right $(P=.64)$ and left limbs $(P=.61)$. When comparing the posttreatment mean values between the study and control groups with regard to the stance and swing phases of the right and left limbs a significant difference in favor of the study group was found $(P \leq .5)$.

Table 5 presents the results of within-group comparison in the stance and swing phases of the right and left limbs, respectively, for the two groups. A significant improvement in all measured variables was observed in both groups when comparing their pre- and posttreatment mean values $(P \leq .5)$.

Table 1. Demographic characteristics of children in the two groups.

\begin{tabular}{lllll}
\hline Items & Study group, mean (SD) & Control group, mean (SD) & Comparison \\
& & & $t$ value $^{\mathrm{a}}$ & $P$ value \\
\hline Age (years) & $7.34(0.7)$ & $7.62(0.64)$ & -1.14 & $.26^{*}$ \\
Weight $(\mathrm{kg})$ & $29.2(2.88)$ & $30.13(2.85)$ & -0.89 & $.38^{*}$ \\
Height $(\mathrm{cm})$ & $126.53(3.09)$ & $127.06(2.63)$ & -0.5 & $.61^{*}$ \\
\hline
\end{tabular}

*Nonsignificant.

${ }^{\mathrm{a}}$ From unpaired $t$ test.

Table 2. Comparison of standing and walking between both groups.

\begin{tabular}{|c|c|c|c|c|}
\hline Period & Control group, mean (SD) & Study group, mean (SD) & $t$ value $^{\mathrm{a}}$ & $P$ value* \\
\hline \multicolumn{5}{|l|}{ Pre } \\
\hline Standing & $0.441(0.099)$ & $0.440(0.138)$ & 0.030 & .97 \\
\hline Walking & $0.253(0.076)$ & $0.250(0.093)$ & 0.107 & .91 \\
\hline \multicolumn{5}{|l|}{ Post } \\
\hline Standing & $0.556(0.105)$ & $0.674(0.100)$ & -3.132 & .004 \\
\hline Walking & $0.310(0.073)$ & $0.4147(0.073)$ & -3.924 & .001 \\
\hline
\end{tabular}

*Significant at $P<.05$.

${ }^{\mathrm{a}}$ From unpaired $t$ test. 
Table 3. Comparison of standing and walking within groups.

\begin{tabular}{|c|c|c|c|c|c|c|c|c|}
\hline \multirow[t]{2}{*}{ Group } & \multicolumn{4}{|l|}{ Standing } & \multicolumn{4}{|l|}{ Walking } \\
\hline & Pre, mean (SD) & Post, mean (SD) & $t$ value $\mathrm{e}^{\mathrm{a}}$ & $P$ value* & Pre, mean (SD) & Post, mean (SD) & $t$ value $^{\mathrm{a}}$ & $P$ value* \\
\hline Control & $0.441(0.099)$ & $0.556(0.105)$ & -13.06 & .001 & $0.253(0.076)$ & $0.310(0.073)$ & -11.244 & .001 \\
\hline Study & $0.440(0.138)$ & $0.634(0.121)$ & -10.72 & .001 & $0.250(0.093)$ & $0.377(0.119)$ & -9.964 & .001 \\
\hline
\end{tabular}

*Significant at $P<.05$.

${ }^{\mathrm{a}}$ From paired $t$ test.

Table 4. Comparison of stance and swing between both groups.

\begin{tabular}{|c|c|c|c|c|}
\hline Site & Control group, mean (SD) & Study group, mean (SD) & $t$ value $^{\mathrm{a}}$ & $P$ value \\
\hline \multicolumn{5}{|l|}{ Right limb } \\
\hline \multicolumn{5}{|l|}{ Pre } \\
\hline Stance & $83.600(2.898)$ & $82.866(3.583)$ & 0.616 & .64 \\
\hline Swing & $16.400(2.898)$ & $17.1333(3.583)$ & -0.616 & .64 \\
\hline \multicolumn{5}{|l|}{ Post } \\
\hline Stance & $79.8000(3.569)$ & $69.0667(6.933)$ & 5.331 & .013 \\
\hline Swing & $20.2000(3.569)$ & $30.93(6.933)$ & -5.331 & .013 \\
\hline \multicolumn{5}{|l|}{ Left limb } \\
\hline \multicolumn{5}{|l|}{ Pre } \\
\hline Stance & $77.600(5.179)$ & $77.6667(5.839)$ & -0.033 & 0.66 \\
\hline Swing & $22.400(5.179)$ & $22.4000(5.865)$ & 0.001 & .61 \\
\hline \multicolumn{5}{|l|}{ Post } \\
\hline Stance & $72.3333(7.752)$ & $67.066(3.990)$ & 2.339 & .12 \\
\hline Swing & $27.666(7.752)$ & $32.933(3.990)$ & -2.339 & .12 \\
\hline
\end{tabular}

* Significant at $P<.05$.

${ }^{\mathrm{a}}$ From unpaired $t$ test.

Table 5. Comparison of stance and swing within groups.

\begin{tabular}{|c|c|c|c|c|c|c|c|c|}
\hline \multirow[t]{2}{*}{ Site } & \multicolumn{4}{|l|}{ Stance } & \multicolumn{4}{|l|}{ Swing } \\
\hline & Pre, mean (SD) & Post, mean (SD) & $t$ value $^{\mathrm{a}}$ & $P$ value & Pre, mean (SD) & Post, mean (SD) & $t$ value $^{\mathrm{a}}$ & $P$ value \\
\hline \multicolumn{9}{|l|}{ Right limb } \\
\hline Control group & $83.6(2.89)$ & $79.8(3.57)$ & 3.37 & .005 & $16.4(2.89)$ & $20.20(3.569)$ & -3.37 & .005 \\
\hline Study group & $82.8(3.58)$ & $69.1(6.93)$ & 6.32 & .001 & $17.13(3.58)$ & $30.93(6.93)$ & -6.32 & .001 \\
\hline \multicolumn{9}{|l|}{ Left limb } \\
\hline Control group & $77.6(5.18)$ & $72.3(7.75)$ & 2.280 & .039 & $22.4(5.18)$ & $27.66(7.752)$ & -2.28 & .039 \\
\hline Study group & $77.6(5.84)$ & $67.1(3.99)$ & 6.448 & .001 & $22.4(5.86)$ & 32.93 (3.9) & -6.37 & .001 \\
\hline
\end{tabular}

*Significant at $P<.05$.

${ }^{\mathrm{a}}$ From paired $t$ test.

\section{Discussion}

\section{Principal Results}

This study investigated the effectiveness of a platform swing walkway on standing and walking tasks and on temporal gait parameters in children with diplegia which is the main spastic type among the different ones reported. Yokochi [16] also reported that spastic diplegia is the common type of $\mathrm{CP}$ that accounts for about $44 \%$ of infants with CP and about $80 \%$ of those with prematurity.

At the end of the treatment period (12 weeks), all children showed significant improvement in gross motor function and temporal gait parameters after walking on the platform swing walkway, which may be attributed to the increase in muscle 
strength and endurance. This result is in agreement with Dean and Shuaib [17] who found that an unstable surface increased muscle endurance and postural control compared with training on a typical surface. Our result is also in agreement with findings of Prosser et al [18] who stated that the choice of specific equipment should be based on clinical objectives (eg, enhancing muscle strength, enhancing reciprocal muscle activation, or proper muscle activity while walking) and functional capacities of the child.

Gait training on the platform swing walkway can increase the motility of the lower limb joints and activation of lower limb muscles, leading to neuromuscular involvement that improves gait ability, resulting in increased gait endurance. This result is in agreement with Bohannon [19] who reported that the activation of hip extensors, knee extensors, and ankle plantar flexors on the affected side is significantly related to maintaining or increasing movement velocity, and thus, an increase in gait velocity reflects an improvement in overall gait abilities.

The significant improvement in GMFM-88 and temporal gait parameters could be attributed to the effect of vestibular stimulation over time which tends to enhance sensory integration, standing, and walking in individuals with CP. These findings support that vestibular stimulation can enhance arousal rates, visual exploratory activity, motor development, balance, and reflex coordination in at-risk infants and in those with developmental retardation disorders [20].

In this study, the improvement in gross motor function and gait parameters may be attributed to the organization of the vestibular system and proprioception. This is in agreement with the finding by Herdman and Clendaniel [21] who stated that peripheral sensory equipment includes a variety of motion sensors (visual, vestibular, and proprioceptive) that send information about head angular velocity and linear acceleration to the CNS, especially to the vestibular nucleus complex and the cerebellum. The CNS interprets these signals and integrates them with other sensory information to accurately predict head and body orientation.

In addition, improvement in motor performance may be attributed to the visual and proprioception input. This fact is supported by findings of Morningstar et al [22], who concluded that visual and vestibular input as well as joint and soft tissue mechanoreceptors play an important role in the regulation of static upright posture. Besides, Prokop et al [23] stated that a combination of visual and proprioceptive information is important for the modulation of walking velocity and indicates that visual information modifies stride length while proprioceptive input maintains a constant stride frequency, leading to a shift in walking velocity.
The findings of this study provide evidence that good sensory integration involves stimulation of the vestibular, proprioceptive, and tactile systems, as a means of exploring new skills. The activities are pitched at a level that stimulates and challenges, yet within the child's capabilities. The efficacy of promoting sensory integration by vestibular stimulation is a key component of integrated sensory therapy. Activities involved in this type of approach lead to the development of a good body scheme, self-image, integration of primitive reflexes, balance, postural stability, motor planning, coordination of both sides of the body, and eye-hand coordination [24]. In this aspect, Lamoth et al [25] found that trunk coordination has an effect on gait parameters and that flexible adaptation in trunk coordination to changes in walking velocity is considered a hallmark of unaffected gait.

Functional training with unstable support is useful for increasing exercise difficulty because unexpected proprietary sensory information and reaction forces in various directions are induced in comparison with training methods on a stable support surface [26-28]. In particular, walking on an unstable support surface such as a balance pad requires more muscle strength and movement around the ankle joint, thereby improving walking speed [28,29].

In this study, functional abilities of children in the study group improved after walking on the platform swing walkway. This result is supported by the work by Jobling and Cuskelly [30] who found that children receiving neurodevelopmental therapy or a combination of neurodevelopmental therapy and other interventions such as vestibular stimulation or sensory integration performed better than those receiving other services.

Some limitations of this study are the relatively small sample size and lack of follow-up. Therefore, larger experimental studies are necessary to define the subcategories of children with CP most likely to benefit from gait training on the platform swing walkway. The strengths of the study are the integration of safety precautions and accommodation during gait training on the platform swing walkway.

\section{Conclusion}

Based on our study results, it can be concluded that platform swing walkway could improve gross motor function and gait patterns in children with spastic diplegia. The platform swing walkway was tolerable at the protocol settings applied and provides the basis for stimulation of safety and efficacy. Future studies should examine the long-term effect of platform swing walkway on locomotor behavior in different types of CP.

\section{Conflicts of Interest}

None declared.

\section{References}

1. Bax M, Goldstein M, Rosenbaum P, Leviton A, Paneth N, Dan B, Executive Committee for the Definition of Cerebral Palsy. Proposed definition and classification of cerebral palsy, April 2005. Dev Med Child Neurol 2005 Aug;47(8):571-576 [FREE Full text] [doi: 10.1017/s001216220500112x] [Medline: 16108461$]$ 
2. Õunpuu S, Gorton G, Bagley A, Sison-Williamson M, Hassani S, Johnson B, et al. Variation in kinematic and spatiotemporal gait parameters by Gross Motor Function Classification System level in children and adolescents with cerebral palsy. Dev Med Child Neurol 2015 Oct;57(10):955-962 [FREE Full text] [doi: 10.1111/dmcn.12766] [Medline: 25926016]

3. Ryan DD, Rethlefsen SA, Skaggs DL, Kay RM. Results of tibial rotational osteotomy without concomitant fibular osteotomy in children with cerebral palsy. J Pediatr Orthop 2005;25(1):84-88. [doi: 10.1097/00004694-200501000-00019] [Medline: 15614066]

4. Carmick J. Forefoot mobility in ankle and foot orthoses: effect on gait of children with cerebral palsy. Pediatr Phys Ther 2013;25(3):331-337. [doi: 10.1097/PEP.0b013e31828e30ac] [Medline: 23685740]

5. Rossignol S, Dubuc R, Gossard J. Dynamic sensorimotor interactions in locomotion. Physiol Rev 2006 Jan;86(1):89-154 [FREE Full text] [doi: 10.1152/physrev.00028.2005] [Medline: 16371596]

6. Chaudhuri S, Aruin AS. The effect of shoe lifts on static and dynamic postural control in individuals with hemiparesis. Arch Phys Med Rehabil 2000 Nov;81(11):1498-1503. [doi: 10.1053/apmr.2000.17827] [Medline: 11083355]

7. Borreani S, Calatayud J, Martin J, Colado JC, Tella V, Behm D. Exercise intensity progression for exercises performed on unstable and stable platforms based on ankle muscle activation. Gait Posture 2014;39(1):404-409. [doi: 10.1016/j.gaitpost.2013.08.006] [Medline: 23999147]

8. Carter JM, Beam WC, McMahan SG, Barr ML, Brown LE. The effects of stability ball training on spinal stability in sedentary individuals. J Strength Cond Res 2006 May;20(2):429-435. [doi: 10.1519/R-18125.1] [Medline: 16686575]

9. Verhagen E, Bobbert M, Inklaar M, van Kalken M, van der Beek A, Bouter L, et al. The effect of a balance training programme on centre of pressure excursion in one-leg stance. Clin Biomech (Bristol, Avon) 2005 Dec;20(10):1094-1100. [doi: 10.1016/j.clinbiomech.2005.07.001] [Medline: 16129528]

10. Bayouk J, Boucher J, Leroux A. Balance training following stroke: effects of task-oriented exercises with and without altered sensory input. Int J Rehabil Res 2006 Mar;29(1):51-59. [doi: 10.1097/01.mrr.0000192100.67425.84] [Medline: $\underline{16432390]}$

11. Bohannon RW, Smith MB. Interrater reliability of a modified Ashworth scale of muscle spasticity. Phys Ther 1987 Feb;67(2):206-207. [Medline: 3809245]

12. Palisano R, Rosenbaum P, Walter S, Russell D, Wood E, Galuppi B. Development and reliability of a system to classify gross motor function in children with cerebral palsy. Dev Med Child Neurol 1997 Apr;39(4):214-223 [FREE Full text] [doi: 10.1111/j.1469-8749.1997.tb07414.x] [Medline: 9183258]

13. Russell DJ, Rosenbaum PL, Avery LM, Lane M. Gross Motor Function Measure (GMFM-66 \& GMFM-88) User's Manual. London, UK: Mac Keith Press; Nov 2002.

14. Baker R. Gait analysis methods in rehabilitation. J Neuroeng Rehabil 2006 Mar 02;3:4 [FREE Full text] [doi: 10.1186/1743-0003-3-4] [Medline: 16512912]

15. Rodríguez I, Martín J. Effect of marker misplacement on 3D Instrumented Gait Analysis kinematic measurements. Gait \& Posture 2014 Jun;39:S112 [FREE Full text] [doi: 10.1016/j.gaitpost.2014.04.154]

16. Yokochi K. Gait patterns in children with spastic diplegia and periventricular leukomalacia. Brain Dev 2001 Mar;23(1):34-37. [doi: 10.1016/s0387-7604(00)00200-x] [Medline: 11226727]

17. Dean N, Shuaib A. Transient ischaemic attacks: unstable, treatable, neglected. Lancet 2007 Oct 20;370(9596):1398-1400. [doi: 10.1016/S0140-6736(07)61449-4] [Medline: 17928045]

18. Prosser LA, Stanley CJ, Norman TL, Park HS, Damiano DL. Comparison of elliptical training, stationary cycling, treadmill walking and overground walking. Electromyographic patterns. Gait Posture 2011 Feb;33(2):244-250 [FREE Full text] [doi: 10.1016/j.gaitpost.2010.11.013] [Medline: 21215636]

19. Bohannon RW. Comfortable and maximum walking speed of adults aged 20-79 years: reference values and determinants. Age Ageing 1997 Jan;26(1):15-19. [Medline: 9143432]

20. Behm DG, Leonard AM, Young WB, Bonsey WAC, MacKinnon SN. Trunk muscle electromyographic activity with unstable and unilateral exercises. J Strength Cond Res 2005 Feb;19(1):193-201. [doi:

10.1519/1533-4287(2005)19<193:TMEAWU>2.0.CO;2] [Medline: 15705034]

21. Herdman SJ, Clendaniel R. Vestibular Rehabilitation. Philadelphia, PA: F.A. Davis and Company; 2014.

22. Morningstar MW, Pettibon BR, Schlappi H, Schlappi M, Ireland TV. Reflex control of the spine and posture: a review of the literature from a chiropractic perspective. Chiropr Osteopat 2005 Aug 09;13:16. [doi: 10.1186/1746-1340-13-16] [Medline: 16091134$]$

23. Prokop T, Schubert M, Berger W. Visual influence on human locomotion. Modulation to changes in optic flow. Exp Brain Res 1997 Mar;114(1):63-70. [doi: 10.1007/p100005624] [Medline: 9125452]

24. An SL. The effects of vestibular stimulation on a child with hypotonic cerebral palsy. J Phys Ther Sci 2015 Apr;27(4):1279-1282 [FREE Full text] [doi: 10.1589/jpts.27.1279] [Medline: 25995606]

25. Lamoth CJC, Stins JF, Pont M, Kerckhoff F, Beek PJ. Effects of attention on the control of locomotion in individuals with chronic low back pain. J Neuroeng Rehabil 2008 Apr 25;5:13 [FREE Full text] [doi: 10.1186/1743-0003-5-13] [Medline: $\underline{18439264]}$ 
26. Lamoth CJC, Stins JF, Pont M, Kerckhoff F, Beek PJ. Effects of attention on the control of locomotion in individuals with chronic low back pain. J Neuroeng Rehabil 2008 Apr 25;5:13 [FREE Full text] [doi: 10.1186/1743-0003-5-13] [Medline: $\underline{18439264]}$

27. Lee SH. The differences between aero step exercises and weight training on posture, physical fitness, balance, and hormone levels in the elderly. In: Master's thesis. Seoul, South Korea: Ewha Womans University; 2007.

28. Song GB, Park EC. Effect of dual tasks on balance ability in stroke patients. J Phys Ther Sci 2015 Aug;27(8):2457-2460 [FREE Full text] [doi: 10.1589/jpts.27.2457] [Medline: 26357425]

29. Kim EJ. The effects of gait training on treadmill and unstable surface and muscular activity in stroke patient. In: Master's degree thesis. Gyeongsan, South Korea: Daegu University; 2009.

30. Jobling A, Cuskelly M. Young people with Down syndrome: a preliminary investigation of health knowledge and associated behaviours. J Intellect Dev Disabil 2006 Dec;31(4):210-218. [doi: 10.1080/13668250600999186] [Medline: 17178533]

\author{
Abbreviations \\ CNS: central nervous system \\ CP: cerebral palsy \\ GMFM-88: 88 -item Growth Motor Function Measure Scale \\ MAS: Modified Ashworth Scale
}

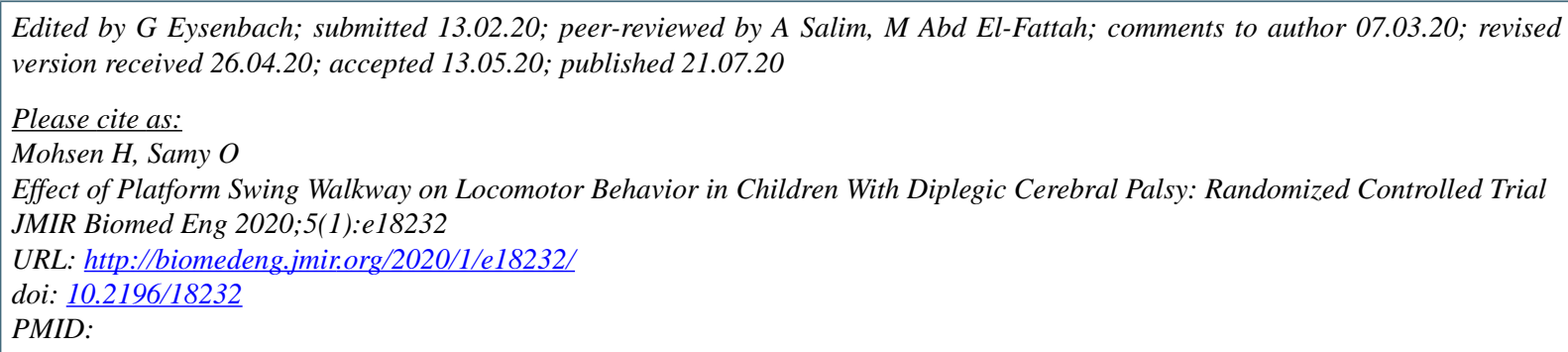

(CHanaa Mohsen, Omnya Samy. Originally published in JMIR Biomedical Engineering (http://biomedeng.jmir.org), 21.07.2020. This is an open-access article distributed under the terms of the Creative Commons Attribution License (https://creativecommons.org/licenses/by/4.0/), which permits unrestricted use, distribution, and reproduction in any medium, provided the original work, first published in JMIR Biomedical Engineering, is properly cited. The complete bibliographic information, a link to the original publication on http://biomedeng.jmir.org/, as well as this copyright and license information must be included. 